\title{
IDEALISMO E REFUTAÇÃO DO IDEALISMO NA FILOSOFIA CRÍTICA DE KANT ${ }^{1}$
}

\author{
Pedro Costa Rego* \\ pedrorego@onda.com.br
}

RESUMO O presente trabalho versa sobre o tema, central no projeto filosófico de Kant, da refutação do idealismo, concentrando-se em dois momentos da Crítica da Razão Pura (CRP): a Dedução Transcendental e a Refutação do Idealismo. Adoto duas hipóteses interpretativas: a primeira, de que a seção da CRP intitulada "Refutação do Idealismo" não esgota o projeto kantiano de uma refutação do idealismo, mas lhe fornece o acabamento, apresentando-se como um desenvolvimento de argumentos aduzidos na Dedução Transcendental. A segunda, de que a refutação kantiana do idealismo assume uma forma bipartida pelo fato de que são essencialmente duas as figuras do idealista que a argumentação implicitamente apresenta como adversário da teoria transcendental do conhecimento. Chamarei essas figuras de idealista cético e idealista da autoconsciência e procurarei demonstrar e discutir a presença, na CRP, de dois distintos movimentos argumentativos anti-idealistas que lhes correspondem nas seções da Refutação e da Dedução. Finalmente, esboçarei a pergunta sobre se e em que medida, entendida na perspectiva de sua forma bipartida, a refutação kantiana completa do idealismo na CRP apresenta uma prova suficiente contra o interlocutor que, apesar de admitir, por hipótese, tanto a possibilidade do conhecimento objetivo quanto seu primado epistêmico em relação à consciência do Eu (consciência dos estados internos ou autoconsciência), subordina o domínio da objetividade à instância transcendental de uma consciência de objetos. 
Palavras-chave Refutação do Idealismo, dedução, apercepção, conhecimento objetivo, Idealismo.

ABSTRACT This paper concerns about Kant's refutation of idealism and focuses on two chief sections of the Critique of Pure Reason: the Transcendental Deduction and the Refutation of Idealism. I shall argue firstly that the first Critique's section named "Refutation of Idealism", instead of exhausting Kant's project of refuting idealism, constitutes its accomplishment, offering a final deployment for some arguments adduced in the Transcendental Deduction. Secondly, I sustain that the refutation-project has two argumentative stages, since the idealist which is implicitly elected as the opponent of Kant's transcendental epistemology has essentially two faces. I shall term the one "skeptical idealist", and the other "self-consciousness idealist", and I'll endeavor to demonstrate accordingly two anti-idealistic lines of argument, both in the Refutation and in the Deduction. Finally, I shall attempt to assign some meaning to the question if kantian complete refutation of idealism amounts to a sufficient proof against a hypothetical opponent who, even though conceding both the possibility of objective cognition and its epistemic primacy towards self-consciousness, subordinates objectivity to the transcendental instance of a consciousness of objects.

Keywords Refutation of Idealism, deduction, apperception, objective cognition, Idealism.

$\mathrm{O}$ estabelecimento bem fundado da doutrina que Kant apresenta como solução dos problemas essenciais da teoria do conhecimento e intitula "idealismo transcendental" depende, em grande medida, do sucesso de duas etapas que fazem parte do projeto da Crítica da Razão Pura (CRP)². A primeira consiste na fundamentação da tese de que nosso conhecimento racional discursivo só pode ter como objeto os fenômenos, isto é, as coisas

2 Como referência para as citações da Crítica da Razão Pura, utilizaremos a edição da Felix Meiner: Kritik der Reinen Venunft, Hamburg, 1990, assumiremos a responsabilidade pelas traduções e, como é praxe, indicaremos no corpo do texto a paginação das edições originais de 1781 e 1787, A e B respectivamente. Para as demais obras publicadas de Kant, utilizaremos preferencialmente a edição da WBD: KANT, I. Werke in zehn Bänden. Hrsg. Wilhelm Weischedel. Darmstadt, Wissenschaftliche Buchgesellschaft, 1983, indicando adicionalmente a numeração das edições originais, onde houver. 
na medida em que são submetidas a determinadas condições epistêmicas ${ }^{3}$, sensíveis e intelectuais, do sujeito transcendental, e não as coisas tais como elas são em si mesmas. A segunda é uma prova da possibilidade do conhecimento fenomênico objetivo através da demonstração de que determinados conceitos e princípios a priori que regulam nossa atividade racional discursiva possuem validade objetiva.

Quanto à primeira etapa, toda gnosiologia comprometida com a tese de que conhecemos em última instância objetos "externos", "coisas em si mesmas", seja ela de viés empirista ou racionalista, é acusada de inconsistência por não sobreviver a uma série de dificuldades que o Idealismo Transcendental pretende ter evitado. Dentre elas, comprometeriam as gnosiologias empiristas, de um lado, o ônus da explicação da possibilidade do próprio conhecimento entendido como um corpo de proposições necessárias sobre objetos, uma vez que teria de ser contingente todo "conhecimento" que tem sua origem última na experiência; de outro, o fracasso das explicações de que aquilo que não passa de uma constatação contingente de ocorrências seja apreensão de estados de coisas em si mesmos, dada a impossibilidade de um acesso direto e privilegiado do sujeito cognoscente a entidades extrarepresentacionais ou extralinguísticas em sentido absoluto. Em relação às teses gerais da gnosiologia racionalista, as dificuldades concentrar-se-iam na suposição dogmática (sic.) da possibilidade de um acesso cognitivo a objetos mediado exclusivamente pelos recursos de uma lógica geral e indiferente às limitações impostas pelas condições sensíveis de todo conhecimento, que são também condições da fenomenalidade do objeto conhecido.

Quanto à segunda etapa, concernente ao problema da justificação de validade objetiva, a posição da CRP é a de que a subordinação das coisas às condições da fenomenalidade não só não compromete como legitima o projeto filosófico de provar a possibilidade do conhecimento objetivo. Justamente na medida em que consideradas segundo formas a priori sensíveis e intelectuais, podem as coisas assumir o estatuto de objetos, se apresentar como distintas das meras representações subjetivas de objetos e se disponibilizar ipso facto como critérios da verdade de nossos enunciados cognitivos. Kant parece

3 A expressão "condição epistêmica" tornou-se, para o bem ou para o mal, a marca registrada da interpretação que Henry Allison propôs para a gnosiologia kantiana e conceito-chave em sua defesa da doutrina do idealismo transcendental contra o sistemático ataque de Paul Guyer. Cf. ALLISON, H. Kant's Transcendental Idealism: an interpretation and defense. (revised \& enlarged edition) New Haven and London: Yale University Press, 2004, pp.3-73, e GUYER, P. Kant and the Claims of Knowledge. Cambridge, Cambridge University Press, 1987, pp.333-415. Sirvo-me da expressão aqui simplesmente como abreviatura para formas a priori da sensibilidade e conceitos a priori do entendimento, sem pretender, em princípio, me comprometer com algum dos lados da polêmica. 
conectar essa prova a uma demonstração de que o conhecimento objetivo, além de possível, possui uma anterioridade, que chamaremos aqui de primado epistêmico ${ }^{4}$, em relação ao autoconhecimento do sujeito, à consciência dos seus estados subjetivos nas sínteses de percepções que ele efetua e à autoconsciência (apercepção).

A primeira etapa, pode-se chamar de uma refutação da doutrina gnosiológica que Kant intitulará "Realismo Transcendental" (em suas diversas versões, eventualmente antagônicas) ${ }^{5}$, caracterizada pela incapacidade de conceber a distinção crítica entre condições epistêmicas da possibilidade do conhecimento e condições ontológicas da possibilidade das coisas mesmas. Quanto à segunda, trata-se, em sentido amplo, do projeto geral kantiano de refutação do idealismo (diagnosticado por Kant em suas versões "problemática", "dogmática" e "empírica"), que se apresenta como um conjunto de argumentos voltados contra aqueles que, defendendo a impossibilidade de um acesso perceptivo imediato ou inferencial-causal a objetos do "mundo exterior", ou bem impugnam ceticamente a possibilidade de todo conhecimento objetivo, ou bem sustentam, seja no nível empírico, seja no transcendental, um problemático primado epistêmico da consciência subjetiva das percepções e da autoconsciência em relação ao domínio da objetividade.

No presente trabalho, interessamo-nos pela segunda etapa.

É razoável esperar de qualquer projeto filosófico comprometido com a tarefa de refutar o idealismo em matéria de conhecimento algum nível de aproximação em relação ao princípio geral da doutrina que a tradição filosófica consagrou com o título de "realismo". Com efeito, nos três momentos em que aborda ex professo o tema na CRP, Kant confronta seu interlocutor com uma gnosiologia realista, ou talvez com o caráter realista de sua teoria transcendental do conhecimento. Como qualquer realismo, o de Kant alega um

4 Tomo emprestada essa expressão, com alguma liberdade, do trabalho de Guido Almeida acerca das semelhanças e distinções entre o Eu penso cartesiano e o Eu penso kantiano: ALMEIDA, G. "Dedução Transcendental: o cartesianismo posto em questão”. In: Analytica. v.3, n¹, 1998, pp.135-156.

$5 \mathrm{Na}$ CRP, as menções à contraposição entre a doutrina do idealismo transcendental / realismo empírico e a do realismo transcendental / idealismo empírico encontram-se na sexta seção da Antinomia da Razão Pura: A490/B518; na subseção da nona seção da Antinomia intitulada "Elucidação da ideia cosmológica de uma liberdade em ligação com a necessidade natural": A543/B571 e na primeira versão do quarto Paralogismo da Razão Pura: A369. Para uma cuidadosa análise do sentido geral da teoria kantiana do conhecimento segundo o fio condutor dessa contraposição, cf. ALLISON, 2004, pp.3-49. 
primado das "coisas", dos "objetos", do "real" - entendidos como o "outro" do sujeito - relativamente ao domínio da "consciência", da "representação", da "ideia". Mas como o título com o qual a gnosiologia crítica de Kant se quer fazer reconhecer é justamente o de "idealismo" (a saber, transcendental), e como sua astronômica metáfora da "inversão copernicana" é flagrantemente uma condenação do realismo filosófico, é preciso que o realismo do projeto refutativo de Kant se explique muito cuidadosamente.

Kant apresenta de modo explícito seu projeto "realista" de uma refutação do idealismo essencialmente em três momentos da CRP. Uma primeira elaboração do tema aparece no quarto Paralogismo da Dialética Transcendental da primeira edição da obra, chamado "Paralogismo da Idealidade (da relação exterior)" (A367-380). Encontramos, em seguida, o título "Refutação do Idealismo" introduzindo uma subseção (B274-279), presente apenas na segunda edição da Crítica, do tópico dedicado aos Postulados do Pensamento Empírico em Geral, situado no interior da Analítica dos Princípios. Finalmente, aparece numa nota do Prefácio a essa mesma segunda edição (BXXXIX-XLI) uma apresentação de objetivos e uma sumária reformulação do que o filósofo assume ser o percurso argumentativo fundamental da tarefa pretendida na seção acima mencionada da Analítica dos Princípios ${ }^{6}$.

Em todas as suas versões, a refutação é apresentada como devendo emergir de um argumento através do qual se pretende que o "jogo do idealismo se volte contra ele mesmo" (B276). Trata-se de mostrar que a consciência que o sujeito tem de si mesmo e de seus estados subjetivos, que se expressa na proposição "Eu penso", pressupõe o conhecimento de estados de coisas objetivos distintos dele. Veremos que essa formulação, geral e válida, em princípio, para as duas versões da Crítica, esconde dificuldades interpretativas e alguma evolução de estratégia e conteúdo entre 1781 e 1787. Mas apesar das diferenças concernentes ao escopo e à radicalidade da prova almejada, parece claro que ambas elegem o idealista empírico como interlocutor e adversário do argumento. Kant caracteriza esse personagem como um realista e dualista transcendental frustrado, que, tendo constatado a impossibilidade do conhecimento das coisas tais como elas são em si mesmas, termina por

6 Consideraremos aqui a seção intitulada "Observação geral acerca do sistema dos princípios" (B288) como parte integrante do tratamento conferido ao tema da refutação no corpo da Analítica dos Princípios. Convém mencionar que por pelo menos seis anos após a publicação da segunda edição da CRP, Kant continuou a se debruçar sobre o tema da refutação do idealismo, período em que formulou ao menos dez reflexões publicadas no Nachlass, quais sejam: R5653, 5654 (após 13 de outubro de 1788); R5709 (final da década de 80); R6311-6317 (outono de 1790) e R6323 (de abril a agosto de 1793). Cada uma é detidamente analisada por Guyer no seu comentário Kant and the Claims of Knowledge: GUYER, 1987, pp.289-329. 
advogar o trancamento da subjetividade na cápsula da sua interioridade representacional e concluir, dogmática ou ceticamente, que o que chamamos de conhecimento objetivo não passa de um fluxo de impressões perceptivas desprovidas de qualquer objetividade ${ }^{7}$.

Acreditamos, entretanto, que essa não é a única versão possível do princípio idealista que rivaliza com o idealismo transcendental kantiano e, se confundido com este, ameaça a inteligibilidade da teoria crítica de Kant como um todo. Propomos que a seção da Crítica intitulada "Refutação do Idealismo", assim como sua versão compactada na nota do Prefácio e sua versão prévia no quarto Paralogismo da edição A, não esgotam o projeto kantiano de uma refutação do idealismo, mas constituem em conjunto o acabamento de uma das duas etapas em que se desdobra esse projeto na Lógica Transcendental. Defendemos que a refutação assume essa forma bipartida pelo fato de que são essencialmente duas as figuras do idealista que a argumentação kantiana implicitamente apresenta na interlocução de sua filosofia transcendental. Uma delas é a do idealista que duvida da possibilidade do conhecimento objetivo; a outra, a do idealista que admite essa possibilidade, mas subordina, de algum modo, o domínio da objetividade cognitiva à instância da autoconsciência.

No que segue, concentraremos nossa análise interpretativa nesses dois momentos da primeira Crítica: a Refutação do Idealismo e a Dedução Transcendental. Procuraremos identificar e caracterizar dois distintos movimentos argumentativos anti-idealistas, correspondentes às duas faces assumidas pelo interlocutor idealista da CRP. Chamaremos essas figuras de idealista cético e idealista da autoconsciência, e discutiremos as hipóteses de que (i) a refutação kantiana do primeiro tem início na Dedução e se conclui na seção da Refutação, e de que (ii) a Dedução contém um projeto de refutação do segundo interlocutor, que não é necessariamente um cético em matéria de conhecimento. Finalmente, esboçaremos a pergunta sobre se e em que medida o projeto gnosiológico-refutativo de Kant, entendido na perspectiva dessa forma bipartida, permanece vulnerável a algum nível de idealismo indesejado. Particularmente, perguntaremos se ele apresenta uma prova suficiente contra o interlocutor que, apesar de admitir, por hipótese, tanto a possibilidade do conhecimento objetivo quanto seu primado epistêmico em relação às duas formas de consciência do Eu elaboradas na obra - consciência dos estados internos e autoconsciência -, subordina o domínio da objetividade à instância transcendental de uma consciência de objetos. Trata-se de investigar se esse

7 A versão dos Paralogismos fornece a mais clara apresentação do interlocutor do projeto refutativo em A369. 
último idealista é Kant ou se, contra ele, Kant precisa fornecer ainda a prova de que a vigência do domínio de uma alteridade radical em relação ao Eu é uma condição tanto da constituição e vigência quanto da auto-referência representativa daquilo que Kant designa como consciência transcendental.

\section{Refutação do idealismo e o problema do ceticismo}

Com base em referências kantianas, de um lado, a posição empirista em matéria de conhecimento é tal que põe em dúvida apenas o apriorismo do que Kant designa como conhecimento objetivo, e não o acesso do sujeito cognoscente a estados de coisas objetivos. Contra ela, Kant teria que provar apenas (o que evidentemente não é pouca coisa) que esse conhecimento está fundado em princípios constitutivos da experiência, pertencentes $a$ priori ao sujeito e, portanto, necessários e universalmente válidos. De outro lado, podemos entender kantianamente como cético aquele pensador que desconfia não apenas da possibilidade de um conhecimento a priori, mas antes possibilidade do conhecimento tout court, isto é, de um acesso, no modo da subsunção de intuições a conceitos, a objetos ou estados de coisas independentes e distintos da ocorrência dos nossos estados perceptivos.

Ora, sabe-se que Kant caracteriza o projeto dedutivo da primeira Crítica como o de fornecer uma prova da validade objetiva da unidade da apercepção e das categorias do entendimento dela derivadas. Mais especificamente, a Dedução deve provar que as categorias são condições da possibilidade do conhecimento de objetos, entendidos como aquilo cuja representação imediata e singular, vale dizer, cuja intuição empírica, se dá numa instância outra e heterogênea em relação àquela a que pertencem essas categorias, isto é, se dá alhures. Sabe-se também que essa instância intuitiva outra é, particularmente em sujeitos racionais finitos como nós, apenas a faculdade da sensibilidade espaço-temporal.

Se nesse horizonte a Dedução se propõe a refutar não apenas o empirismo gnosiológico, mas também o ceticismo em matéria de conhecimento ${ }^{8}$, seu procedimento completo deve consistir essencialmente: (i) numa demonstração de que as categorias, enquanto conceitos a priori, são condições da possibilidade do conhecimento de dados intuídos; (ii) numa demonstração

8 Para uma defesa de que o projeto dedutivo da CRP assume como interlocutor privilegiado o pensador cético em matéria de conhecimento, cf. Cf. McCANN, Edwinn. "Skepticism and Kant's B Deduction". In: History of Philosophy Quarterly 2 (January 1985) pp.71-89. Cf. AMERIKS, K. "Kant's Transcendental Deduction as a Regressive Argument". Kant-Studien 69, 1978, para uma defesa de que o argumento da Dedução é dirigido antes contra o filósofo empirista. 
dessa validade objetiva voltada para um interlocutor que admite ainda menos que um acesso cognitivo a posteriori a objetos, vale dizer, para alguém que admite, no máximo, ter intuições. Acreditamos que a Dedução se propõe a cumprir essa tarefa (e a cumpre apenas parcialmente, como veremos adiante) adotando a estratégia que consiste em derivar a possibilidade do uso (objetivo) das categorias a partir da premissa de uma consciência pré-judicativa de um diverso de representações temporais.

Podemos encontrar nos parágrafos da Dedução no mínimo o esboço de dois caminhos argumentativos que, partindo de uma premissa em princípio cética (a mera consciência de intuições), apontam para uma prova da possibilidade do conhecimento objetivo. Em questão, estará sempre o que o $\S 18$ chama de uma relação de derivação entre a unidade subjetiva e a unidade objetiva da apercepção?.

O primeiro caminho, problemático, creio, assumiria a forma de um argumento ad hominem que implicaria duas decisões interpretativas prévias: primeiro, que a chamada unidade subjetiva da apercepção seja compreendida não como ordenação associativa contingente de dados do sentido interno, mas como a unidade de um reconhecimento judicativo de estados subjetivos. Poderíamos dizer com algumas ressalvas: como a unidade de juízos de percepção. Segundo, que se aceite a definição de juízo do $\$ 19$, chamada nos Primeiros Princípios Metafísicos da Ciência da Natureza (PPM) de "definição precisamente determinada de juízo": "a forma lógica de todos os juízos consiste na unidade objetiva da apercepção dos conceitos contidos neles"10.

Isso aceito, o argumento assim se construiria: primeiro, a mencionada "definição precisamente determinada" determina que todo juízo possui validade objetiva, comprometendo-se com uma pretensão de verdade, ou, com uma pretensão de caracterização universalmente válida de estados de coisas objetivos. Isso tem de valer inclusive para aqueles juízos a respeito do que Gerold Prauss chamou de "objetos subjetivos" ". Segundo, a unidade subjetiva da apercepção, enquanto apercepção empírica, seria um juízo acerca de objetos do sentido interno, e não uma consciência pré-categorial e meramente associativa $^{12}$. Conclusão: a mera atualização de minha consciência de estados

9 Nos quarto parágrafos que seguem, apresento um resumo das principais conclusões de meu artigo acerca do percurso estratégico da Dedução Transcendental B, intitulado "Apercepção subjetiva e conhecimento objetivo: uma leitura sobre o lugar do §18 na estratégia da Dedução B da Crítica da Razão Pura". In: Manuscrito - Revista Internacional de Filosofia. Unicamp/CLE, v.34, n³, jul-dez. 2011.

10 KANT, PPM, 8, p.21, AXIX.

11 Cf. PRAUSS, G. Erscheinung bei Kant. Berlin, de Gruyter, 1971, pp.292-321.

12 Há motivos para sustentar que a expressão "unidade empírica da apercepção" expressa em Kant uma forma categorial e judicativa de consciência, distinta tanto do sentido interno, quanto do conhecimento de 
subjetivos garante que suponho a possibilidade do conhecimento objetivo, o que só pode se dar mediante a atividade de regras a priori de determinação de relações objetivas entre as representações, isto é, mediante a atividade das categorias do entendimento. A explicação é que não posso, pelo menos do ponto de vista da razão, ao mesmo tempo julgar, isto é, erguer uma pretensão de verdade, sem supor que seja possível isso que pretendo, a saber, conhecer objetivamente. Ora, pretensão de verdade é justamente o que o adversário da Dedução considera uma ilusão. Assim, esse adversário acabaria afirmando precisamente o que ele pretende negar, a saber, que tem sentido pretender conhecer objetivamente.

Sucintamente, as dificuldades que se pode atribuir a essa linha argumentativa: a primeira consiste no caráter meramente definitório do argumento no que concerne à noção de juízo. Afinal, o adversário da Dedução não precisa admitir que, ao expressar pensamentos através da ligação de representações, esteja se servindo do discurso como um meio para apreender a existência objetiva de estados mentais. A segunda e mais importante: no argumento, ainda que se aceite a natureza judicativa da consciência dos nossos estados internos, não é exatamente a possibilidade do conhecimento objetivo o que está sendo demonstrado como uma condição da descrição conceitual dos estados mentais: é, antes, a necessidade de uma suposição de natureza modal (ou talvez mesmo psicológica). A explicação é que, segundo o argumento, para julgar sobre minhas percepções, não posso deixar de acreditar, em virtude do caráter no mínimo assertórico de todo juízo tomado isoladamente, que é possível conhecer objetos. Mas isso não exclui que seja impossível conhecer objetos, e que minha suposição contrária esteja simplesmente equivocada. Ora, a prova a que parece almejar Kant no projeto geral da Dedução não é a da necessidade de uma crença, mas a da necessidade de uma possibilidade, a qual necessidade independe, a princípio, da crença nela e logicamente a precede.

O segundo caminho argumentativo indicado na Dedução parece apontar para o caráter derivado in concreto da unidade subjetiva da apercepção evitando as dificuldades acima. Tratar-se-ia, na Dedução, de fornecer uma prova de que no ato de consciência subjetiva de minhas intuições, suponho a possibilidade

objetos stricto sensu. Para Paton, "Kant sublinha o fato de que os atos judicativos em que a apercepção empírica se manifesta são o reconhecimento ou memória de representações ou estados mentais passados, o que parece incluir (...) o conhecimento dos nossos estados mentais (PATON, H. J. Kant's Metaphysic of Experience. New York: George Allen \& Unwin LTD, The Humanities Press, 1965, $4^{\text {th }}$ impression, p.402, nosso grifo) Para Allison, "Kant considera apercepção empírica como equivalente a autoconhecimento empírico, isto é, como um modo de consciência pelo qual representamos nós mesmos a nós mesmos como objetos do sentido interno" (ALLISON, H.E. Kant's Transcendental Idealism: an interpretation and defense. New Haven and London: Yale University Press, 1983, p.156, nosso grifo). 
do conhecimento de estados de coisas objetivos não simplesmente porque julgo e/ou aplico a cópula "é"; antes, esse ato de consciência é condicionado pela aplicação das categorias, e somente por isso aplico a cópula "é". Isso significa: qualquer nível de consciência de ocorrências sensíveis é eminentemente categorial, ainda que, no registro do sentido interno, a atuação das categorias não resulte na produção de conhecimento objetivo. Demonstrado, portanto, o uso "pré-reflexivo" das categorias - que H. Allison chama "papel protoconceitual das categorias" como "regra de apreensão" de dados intuídos, e a que B. Longuenesse se refere com a expressão "uso das categorias como meros guias de sínteses"13 -, pode-se então pretender provar que esse uso tem como pressuposto a possibilidade de seu uso objetivo, pelo que a Dedução atingiria sua finalidade. O que essa interpretação sugere é que é possível manter a tese forte kantiana da heterogeneidade dos poderes representativos - isto é, que posso ter intuições sem pensar atualmente as intuições que tenho - e subordinar a algum nível de pensamento conceitual não a receptividade dos dados, mas a consciência dos dados como recebidos. Assim, as categorias não seriam apenas condições da possibilidade do conhecimento objetivo dos dados intuídos. Elas seriam isso pelo fato mesmo de que são, antes, condições da possibilidade de toda e qualquer consciência representativa de intuições sensíveis, de tal modo que, a partir de agora, o problema da distinção entre subjetivismo e objetividade seria o da distinção entre o uso pré-reflexivo das categorias e seu uso objetivo-cognitivo.

Argumentativamente consistentes ou não, esses dois caminhos visam a fornecer a mesma prova: admitida a mera consciência de representações (ou intuições), entendida como a econômica concessão do cético, deve-se admitir o domínio da objetividade - seja porque toda consciência empírica é categorial (ou protocategorial), seja porque o que se admite aqui como premissa é um auto-conhecimento judicativo. Pergunta-se então: em que medida a argumentação kantiana contra o ceticismo em matéria de conhecimento

13 Comentando a leitura de Longuenesse sobre esse ponto, Allison afirma que elas "operam em dois níveis: pré-reflexivamente, enquanto funções lógicas do juízo guiando as sínteses sensíveis da imaginação, e pós-reflexivamente, enquanto conceitos sob os quais objetos são subsumidos em juízos de experiência objetivamente válidos" (ALLISON, H. Kant's Theory of Taste. Cambridge, Cambridge University Press, 2001, p.16, nossos grifos). A tese da comentadora é a de que há em Kant a noção de uma "aplicação inicial" das categorias, em que elas se acham apenas "incutidas na mente na condição de funções lógicas” guiando a síntese sensível, e de uma segunda aplicação, em que elas assumem a função de "full-fledged concepts" e respondem por uma "combinação discursiva objetivamente válida" (LONGUENESSE, B. Kant and the Capacity to Judge. Princeton and Oxford: Princeton University Press, 1998, p.244). Para as passagens citadas no corpo do texto, cf. ALLISON, 2004, p.196 e LONGUENESSE, B. "An Interview with Béatrice Longuenesse". In: The Dualist: Stanford's Undergraduate Journal of Phylosophy, Vol. XII, No 1, Autumn 2005, 67-81, p.74. 
teórico, como propusemos acima, começa na Dedução, mas só se consuma na Refutação do Idealismo?

A passagem da premissa do $\S 16$ - a noção de um múltiplo de representações minhas em geral - para a do §18 - o sentido interno entendido como consciência de um múltiplo de representações temporais - define a estratégia da Dedução de inferir a unidade objetiva da apercepção (portanto, o conhecimento objetivo) a partir da consciência empírica de nossos estados sucessivos. Com efeito, a segunda parte da Dedução, particularmente o §26, é uma explicação de como, através da síntese transcendental da imaginação, a unidade originária de apercepção se conecta com a intuição pura do sentido interno, isto é, o tempo.

Tudo indica, entretanto, que Kant reconheça que a subordinação de representações temporais às regras necessárias da apercepção judicativa ainda é menos do que uma demonstração da possibilidade do conhecimento objetivo. Esta depende, é verdade, de uma prova de que podemos ordenar nossas representações sucessivas segundo regras necessárias provenientes da unidade da apercepção originária. Mas depende também de uma prova de que essas representações remetem ao objeto. Para Kant, isso equivale a demonstrar que as regras originárias da apercepção também se aplicam àquilo que é dado alhures (andertwärts) ${ }^{14}$, que se nos antepõe (dawider ist) ${ }^{15}$, que é portanto "outro" em relação ao sujeito. Até que isso fique demonstrado, representações temporais regradas por princípios intersubjetivos podem consistir em conteúdos exclusivamente mentais.

Como bem se sabe, o meio pelo qual nos relacionamos de modo imediato com a alteridade objetiva é o espaço, definido na Estética Transcendental como forma do sentido externo. Sendo assim, a prova da possibilidade do conhecimento objetivo em sentido estrito iniciada na Dedução permanece inconclusa até que se demonstre a ligação entre a atuação das categorias na síntese das representações temporais e sua aplicação a objeto dados no espaço. Parece ser isso a que Kant se propõe nas seções da CRP dedicadas diretamente ao tema da refutação do idealismo. Tudo indica que Kant pretenda aqui completar o projeto dedutivo mostrando que a consciência que temos 
dos nossos estados internos temporais, cuja sujeição a regras necessárias fora demonstrada (sic.), envolve de algum modo a referência a uma alteridade em relação a nós indispensável na constituição da objetividade. Consideremos então as versões da Refutação em sua argumentação contra o idealista cético.

\section{O quarto Paralogismo da CRPA}

O objetivo de Kant no quarto Paralogismo A da CRP é fornecer, contra o idealismo empírico, uma prova de que a realidade do "mundo exterior" não é duvidosa; antes, ela é tão certa quanto a das representações de nossa experiência interna. Sua estratégia consiste, em primeiro lugar, na defesa da doutrina do idealismo transcendental como capaz de disponibilizar um domínio de objetividade que é ao mesmo tempo "exterior" em relação ao âmbito de uma consciência de estado privados e "interior" relativamente ao objeto transcendental. Em segundo lugar, na refutação da hipótese de que, apesar de logicamente admissível, o acesso a uma objetividade espacial não se realizaria de fato, estando em seu lugar sempre produtos ficcionais da imaginação.

Quanto à primeira etapa, trata-se, de saída, de aproximar o idealista a ser refutado do pressuposto fundamental do realismo transcendental. Kant caracteriza esse interlocutor, portanto, como partidário da doutrina segundo a qual espaço e tempo são condições das coisas em sua vigência ontológica, e o conhecimento é entendido como conhecimento delas, consideradas "em si mesmas", como os legítimos objetos exteriores ao sujeito.

Ao defender a possibilidade do conhecimento das coisas tais como são em si mesmas, o realista transcendental é chamado "dualista" em sentido transcendental, título que designa um partidário da doutrina de que àquelas coisas, consideradas como os objetos exteriores, temos um acesso perceptivo imediato. Tese de Kant: o reconhecimento da indemonstrabilidade desse acesso torna o realista transcendental um idealista empírico. Não porque o faria desconfiar do alvo do conhecimento objetivo (as coisas em si mesmas), mas porque o faria negar a ou duvidar da possibilidade de o atingir. Dualista transcendental decepcionado, o idealista empírico passa a advogar a reclusão do sujeito no interior do domínio da consciência e conclui, dogmaticamente ou não ${ }^{16}$, que o que chamamos de conhecimento objetivo não passa de um fluxo de impressões desprovidas de objetividade. 
Em seguida, Kant se propõe a desfazer a assimilação, que seria o apanágio da gnosiologia metafísica e ontológica de toda a tradição, entre objeto cognitivo e objeto transcendental. Do ponto de vista da reflexão filosófico-transcendental, não só não podemos ter nenhum acesso, seja perceptivo imediato, seja inferencial-causal, às coisas consideradas independentemente do domínio subjetivo-representacional, como tampouco se define o conhecimento como correspondência do pensamento em relação às coisas tais como elas são em si mesmas. Assim, em sentido transcendental, seria correta a doutrina crítica chamada idealismo, que recusa o dualismo e a cognoscibilidade do objeto transcendental, mantendo o sujeito cognoscente dentro dos limites do domínio representacional. O que podemos conhecer, afirma Kant oito vezes na seção dos Paralogismos, são "meras representações".

Finalmente, Kant empenha-se por mostrar que essa restrição idealista do horizonte da cognoscibilidade ao domínio meramente representacional não é, em todos os níveis de reflexão, um obstáculo ao "conhecimento objetivo" do "mundo exterior". É que o universo das meras representações pode ser considerado em referência ao sentido interno apenas, pelo qual nos tornamos conscientes dos nossos estados subjetivos, ou em referência ao sentido externo, pelo qual referimos aquelas ao objeto entendido como algo "outro" e "externo" em relação ao sujeito. Que, em sentido transcendental, o objeto do conhecimento pertença ao domínio da idealidade (ao domínio subjetivorepresentacional), não implica que ele esteja desqualificado ao estatuto de objeto externo, mundo exterior ou coisa fora de nós (ausser uns). Ao contrário, o pertencimento, em sentido transcendental, ao domínio da idealidade é a condição de uma "exterioridade" legitimamente cognitiva. Ou: a interioridade transcendental do objeto do conhecimento é a condição de sua exterioridade empírica relativamente à consciência que tem o sujeito de seus estados internos. Assim se explica a tese kantiana de que o idealista transcendental é também um realista e um dualista, a saber, em sentido empírico (A370).

$\mathrm{O}$ argumento proposto por Kant para, no quadro do idealismo transcendental, desmontar a hipótese da ficcionalidade de nosso acesso a objetos espaciais se constitui nos seguintes passos:

(i) todo o trabalho ficcional da imaginação opera necessariamente sobre a base de percepções espaciais (A373-4); (ii) a simples percepção espacial necessariamente representa algo de real no espaço ${ }^{17}$, e (iii) o caráter perceptivorepresentacional dessa realidade a torna tão indubitável e imediatamente 
acessível quanto a realidade dos nossos estados internos ${ }^{18}$. Assim, admitindose, como é plausível esperar de um interlocutor idealista empírico, que temos consciência imediata de nossos estados representacionais internos, e que é o estatuto representacional destes que torna sua realidade imediatamente acessível, o fato de os estados de coisas chamados externos serem, na perspectiva idealista transcendental, igualmente perceptivo-representacionais tornaria a realidade destes tão imediata e indubitável quanto à daqueles. Se, ademais, toda operação imaginativa se processa sobre a base de percepções de realidade espacial, deveríamos concluir que nossa autoconsciência implica a realidade do chamado mundo exterior.

\section{A Refutação do Idealismo na CRP B}

Assim como no texto dos Paralogismos A (367), a Refutação da edição B adota, curiosamente, Descartes como interlocutor privilegiado. $\mathrm{O}$ idealismo cético que ele sustenta de acordo com o primeiro texto torna-se aqui um idealismo material (leia-se: empírico) ${ }^{19}$ problemático (B274), tão louvado quanto aquele, por ser "racional e conforme uma maneira de pensar filosoficamente rigorosa" (B275). Mas esse acréscimo da edição B apresenta, em relação à refutação de 81, algumas modificações estratégicas e conceituais importantes.

Em primeiro lugar, o novo argumento parece substituir a preocupação do quarto Paralogismo A com o problema da existência / realidade do "mundo exterior" pela preocupação com a chamada "experiência externa". "A prova exigida", anuncia Kant, "deverá, pois, mostrar que temos também experiência e não apenas imaginação das coisas exteriores" (loc.cit.). Aparentemente, portanto, a demonstração prevista é mais contida do que o percurso da primeira edição. Mas dado que esta última, como vimos, termina limitadamente focada nessa mesma "experiência" representacional do mundo externo, a versão B parece ao fim e ao cabo se anunciar cúmplice do princípio da internalização do objeto do conhecimento, e tão tímida quanto a versão A em relação à ontologia do "fora de nós". Todavia, em flagrante confronto com essa aparência, a "Prova

18 Allison identifica na Refutação B uma estratégia que radicalizaria a opção argumentativa da versão dos Paralogismos A acima descrita, chamada pelo comentador de reductio da posição cética. O que tornaria a experiência externa solidária da interna não seria exatamente seu caráter representacional, mas antes o fato de ambas possuírem "o mesmo estatuto epistêmico" (ALLISON, 2004, p.295), se tratarem "duas facetas da mesma experiência", sendo "toda experiência interna (...) também em parte externa". Isso implicaria que "a experiência interna não pode ser algo verdadeiro e a externa, que a condiciona, algo ilusório” (op.cit. p.297).

$19 \mathrm{Na}$ nota do Prefácio, o idealismo a ser refutado é chamado "psicológico" (BXXXIX). 
do Teorema" em B275 defende, mais audaciosamente, que todo o quarto Paralogismo, a "existência de coisas reais que percebo fora de mim", que "não [são] (...) simples representação de uma coisa exterior a mim" (B275-6).

Em segundo lugar, a nova versão, à diferença da antiga, pretende mostrar que a mencionada "experiência externa" não é nem apenas possível, nem apenas imediatamente acessível; ela é mais imediatamente acessível do que a "experiência interna", isto é, do que a consciência que tem o sujeito dos seus estados internos no tempo. Kant anuncia nos seguintes termos as teses idealistas a serem refutadas: primeiro, a tese de que "a única experiência imediata é a experiência interna", e segundo, a de que "a partir dela inferimos [a existência das] coisas externas". Em vez disso, tratar-se-á de mostrar que a "experiência externa a rigor é imediata", enquanto "somente por seu intermédio é possível (...) a experiência interna" (B276). Nessa inversão consiste o projeto refutativo de mostrar que "o jogo do idealismo se volta contra ele, com a maior razão" (loc.cit).

Em terceiro lugar, a estrutura argumentativa que conduz a essa inversão é significativamente distinta da estratégia dos Paralogismos A. Enquanto na primeira edição o caráter representacional da experiência externa a torna solidária da interna, na segunda, a experiência externa é apresentada como o permanente relativamente ao qual se faz possível a consciência do fluxo de nossos estados internos temporalmente determinados ${ }^{20}$.

Considerando em conjunto o texto da Refutação e sua reelaboração na nota do Prefácio B, a argumentação se desdobra nos seguintes passos: (i) na medida em que tenho consciência dos meus estados internos, identifico-os como ocupando posições temporais determinadas, que fazem da "consciência empírica da minha representação" (BBXLn) uma "consciência empírica da minha existência" (loc.cit) determinada; (ii) as posições temporais dos meus estados, e com isso minha existência, só podem ser determinadas relativamente a algo de permanente; (iii) nada há de permanente "em mim" capaz de desempenhar o papel de contraponto fixo da sucessão temporal de meus estados internos. Toda suposta "representação permanente [em mim] (...) pode ser muito variável e mutável (...), mesmo as representações da matéria" (BBXLIn). É bem verdade que a consciência intelectual da minha existência

20 Segundo Allison, Kant procede a essa demonstração por duas vias: pela primeira, considerada pelo comentador como "manifestamente inadequada", o permanente espacial seria apresentado como "algo (...) devendo ser pressuposto a fim de darmos conta de algumas das representações que de fato possuímos", a saber, as representações do sentido interno temporalmente determinadas. Pela segunda via (cf. nota 18), a experiência externa teria sua realidade provada no fato de constituir a faceta externa da própria experiência interna (ALLISON, 2004, p.297). 
na representação Eu sou apresenta-me como um Eu permanente. Todavia, não desempenha a função de conferir determinação às posições temporais de meus estados internos porque não é consciência intuitiva e, por conseguinte, não se representa o Eu permanente como determinado em sua existência; (iv) conclusão: a consciência que tenho das representações do meu sentido interno só é possível pela existência de um permanente externo extra-representacional.

Convém mencionar o modo como Kant se refere a essa última exigência, que parece realmente contrastar com os resultados da aplicação do princípio de internalização na versão A. No texto da Refutação, Kant afirma que "a percepção desse permanente só é possível através de uma coisa exterior a mim, e não pela simples representação de uma coisa exterior a mim" (B275, grifos do autor), e que "a determinação da minha existência no tempo só é possível pela existência das coisas reais..." (B276). Já na nota do Prefácio, assevera que "tenho (...) segura consciência de que há coisas exteriores a mim que se relacionam com o meu sentido..." (BBXLIn); que "a própria experiência interna depende de algo de permanente que não está em mim e que portanto só pode ser exterior a mim, e com o qual tenho que me considerar relacionado" (BBXL-In); que tenho um "sentido externo [que] é já em si relação da intuição a algo real fora de mim..." (BBXLn); finalmente, que meu sentido interno prova que tenho "a representação de algo permanente (...) que tem que ser uma coisa distinta de todas as minhas representações e exterior a mim”, e que "não é idêntico a uma representação permanente" (loc.cit. São de Kant todos os grifos das citações) $)^{21}$.

21 Chama a atenção que Kant em momento algum retome explicitamente a distinção dos Paralogismos, supostamente tornada necessária pela equivocidade da expressão, entre um "fora de nós" em sentido empírico, cognitivamente acessível de modo imediato, e um "fora de nós" em sentido transcendental, que é para nós um mero "nada" (A370). O filósofo parece referir-se agora indiscriminadamente ao contraponto permanente das transformações da "experiência interna" como "coisas reais exteriores a mim"(BBXLIn), que não são representações de coisas, e como "experiência externa em geral" (B278-9): "objetos no espaço fora de mim, cuja existência é provada pela simples consciência, mas empiricamente determinada, de minha própria existência" (nosso grifo; adaptação sintática da fórmula do Teorema da Refutação B. Literalmente: "A simples consciência, mas empiricamente determinada, de minha própria existência prova a existência de objetos no espaço fora de mim" (B275)). Essa omissão se presta a distintas interpretações. A primeira delas explora o fato de que em muitas das passagens acima citadas a referência ao "fora de nós" se deixa ler ou bem como remissão ao sentido externo, ou bem como um pressuposto necessário da consciência, e não como asserção de existência em sentido ontológico. Nesse sentido, Kant daria por trivial e consumada a referida distinção e se permitiria trabalhar apenas com a primeira acepção de "mundo externo", o mundo externo internalizado das representações espaciais. Nesse caso, a recusa da "simples representação de uma coisa exterior" (a mais forte citação em contrário) como contraponto da experiência interna seria interpretada como a recusa dos produtos representacionais da imaginação, mas não como a recusa do caráter representacional dos objetos espaciais. Alternativamente, poder-se-ia aduzir a interpretação de que o silêncio da Refutação B a respeito da distinção entre o "fora de nós" representacional e o "fora de nós" absoluto expressa o pressuposto kantiano tácito da cumplicidade entre essas instâncias. Nessa direção, seria uma posição de Kant, eventualmente estabelecida na Estética Transcendental, que qualquer referência à "experiência externa", enquanto conhecimento de objetos dados na forma espacial de nossa intuição 
Seja como for, sublinhe-se, para nossos propósitos no momento, que Dedução e Refutação incorporam o projeto de demonstrar a possibilidade do conhecimento objetivo contra o ceticismo gnosiológico. A primeira, pretendendo demonstrar que a consciência subjetiva dos nossos estados intuitivos internos envolve o exercício das categorias, entendidas como regras universais e necessárias derivadas da unidade da apercepção transcendental; a segunda, propondo-se a provar que aquela mesma consciência empírica submetida às categorias supõe um algo (permanente, nos termos da versão B) externo que é propriamente o foco do conhecimento objetivo. Ambos os movimentos consistem em argumentos ad hominem, o primeiro partindo da premissa da unidade subjetiva da apercepção para concluir a possibilidade de sua unidade objetiva, entendida como regulação necessária; o segundo, da premissa da consciência empírica dos nossos estados internos para concluir existência de um "fora de nós" mais imediatamente acessível do que eles. Resta mostrar que o idealista cético a quem, em conjunto, Dedução e Refutação pretendem se opor não é o único adversário da gnosiologia transcendental de Kant. Trata-se, então, de esclarecer em que medida a primeira dessas seções também apresenta um argumento contra o que chamamos acima de idealista da autoconsciência.

\section{Refutação do idealismo - o problema da autoconsciência}

Segundo nossa reconstrução, as seções da Refutação tomadas em conjunto sustentam (i) que a consciência empírica que o sujeito tem dos seus estados

sensível, implica necessariamente uma referência ao objeto externo transcendental, em si incognoscível (essa leitura sublinharia a supracitada afirmação do Prefácio de que o "sentido externo é já em si relação da intuição a algo real fora de mim..." (BBXLn) ... em sentido transcendental). Assim, o permanente suposto pela consciência interna se constituiria a partir de algum nível de conjunção entre o objeto representacional do sentido externo e o objeto em si, abstração feita das condições subjetivas da fenomenalidade. Especificamente para os fins de uma refutação do idealismo, bastaria aduzir o argumento da permanência do externo tout court, confiando a outra parte a discussão acerca de sua problemática constituição. Finalmente, uma terceira linha interpretativa, comumente aceita em virtude do significativo número de passagens textuais que infirmam a estratégia dos Paralogismos A de internalização do "mundo externo", advoga uma explícita mudança de foco no argumento refutativo. Segundo essa leitura, a edição de 1787 estabeleceria como o objetivo da prova a demonstração da existência do mundo externo ontologicamente independente do domínio representacional. Nos termos de uma das adeptas, "a preocupação a que se dirige a Refutação do Idealismo na segunda edição da Crítica" se expressa na pergunta: "Que razão temos para pensar que objetos externos assim representados são externos não apenas no sentido de serem (representados) no espaço, mas também no sentido mais forte de serem ontologicamente distintos dos estados mentais por meio dos quais temos acesso a eles?” (LONGUENESSE, B. "Kant's 'I think' versus Descartes' 'I am a thing that thinks'”. In: Kant and the Early Moderns. Ed. Longuenesse, B. \& Garber, D. Princeton, Princeton University Press, 2008, p.28). Veremos adiante que é no horizonte dessa problemática hermenêutica do "fora de nós" que se formula nossa questão final sobre a possibilidade de um indesejável idealismo remanescente do projeto refutativo kantiano. 
internos é condicionada pela representação de um elemento permanente espacial "externo", que será caracterizado como objeto do conhecimento em sentido estrito, e (ii) que nossa consciência desse permanente externo é tão imediata quanto ou mais imediata do que a consciência dos nossos estados internos. Ocorre, entretanto, que, segundo os $\S \S 16-18$ da Dedução, esta última também só é possível sob a pressuposição de que posso me referir a mim mesmo como a unidade do ato de pensamento e como sujeito idêntico e numericamente uno de meus estados representacionais. Chamaremos aqui essa auto-referência - o "Eu penso" do §16 - de autoconsciência, consciência de si, ou apercepção (pura). De que modo se deve compreender a relação "principial" da autoconsciência com o conhecimento objetivo, é algo que Kant muito se esforçará por esclarecer ao longo da Dedução e, sobretudo, algo de que depende essencialmente sua posição enfaticamente divergente em relação à (sua compreensão da) doutrina cartesiana do cogito.

Do ponto de vista que aqui nos interessa, três pontos merecem atenção especial.

Em primeiro lugar, deve-se reconhecer o esforço de Kant - do qual os $\S \S 24$ e 25 da Crítica talvez sejam o maior exemplo - por distinguir o que em princípio o cartesianismo identifica: o princípio transcendental da apercepção e a consciência empírica (cognitiva ou não) que temos dos nossos estados internos. Enquanto, para Kant, o primeiro consiste na consciência estritamente intelectual da unidade do ato do pensamento, a última resulta da síntese de intuições do sentido interno segundo o modo como ele é "afetado" pela primeira ${ }^{22}$.

Em segundo lugar, o que as seções da Refutação pretendem desqualificar é o primado de uma forma de consciência dos estados internos $-e$ não $o$ da autoconsciência (apercepção) - em relação à consciência dos objetos do sentido externo ${ }^{23}$. Mais precisamente, trata-se de inverter o primado, supostamente cartesiano, da experiência interna relativamente à externa,

22 "Com o nome de síntese transcendental da imaginação", que é um "exercício de espontaneidade determinante (...) podendo, por conseguinte, determinar a priori o sentido quanto à forma e de acordo com a unidade da apercepção" (B151/2, nosso grifo), "o entendimento exerce, pois, sobre o sujeito passivo de que é a faculdade uma ação da qual podemos justificadamente dizer que por ela é afetado o sentido interno" (B153-4, grifos do autor).

23 Concordamos aqui com a interpretação de Lachièze-Rey, segundo a qual "o Eu cuja posição será tornada solidária à do mundo exterior não é o do Eu penso, eu sou", se considerarmos, é claro, este último como expressão da apercepção. Sublinhe-se, ademais, que o comentador se refere aqui especificamente ao projeto da Refutação, motivo pelo qual manifestamos nosso acordo. E acrescenta: "não poderia se tratar [na Refutação] de subordinar a consciência transcendental aos objetos do mundo exterior...”. A explicação, todavia, merecerá alguma crítica no que segue: "uma vez que estes não são senão fenômenos, cuja inteira constituição formal emana precisamente dessa consciência” (LACHIÈZE-REY, P. L'idéalisme kantien. Paris: J. Vrin, 1972, p.63, apud. ALMEIDA, 1998, p.139, nosso grifo). 
o que significa kantianamente: o primado do autoconhecimento intuitivo relativamente ao conhecimento objetivo stricto sensu.

Terceiro: algumas passagens das duas versões da Dedução parecem justamente asserir o primado da autoconsciência (apercepção) em relação ao conhecimento de objetos externos. Um consistente recenseamento delas se encontra em dois artigos de Guido Almeida sobre a Dedução Transcendental ${ }^{24}$, dois quais cito apenas duas, uma de cada edição da Crítica: na versão A, Kant afirma que "a apercepção pura fornece um princípio da unidade sintética do múltiplo em toda intuição possível" (A116) ${ }^{25}$; sobre a edição de 87 , cito o comentador: "no próprio título do $\S 17$, lemos: 'o princípio da unidade sintética da apercepção é o princípio supremo de todo o uso do entendimento’ (B136), $\mathrm{o}$ entendimento sendo definido em seguida neste mesmo parágrafo como 'o poder dos conhecimentos' (B137) ${ }^{26}$.

Considerados esses três pontos, parece haver motivos para acreditar que a autoconsciência se apresente tanto como condição da consciência empírica dos nossos estados internos, como também - ou melhor, justamente na medida em que é - anterior, principial e quiçá genética em relação ao conhecimento objetivo. Com efeito, que tanto ela (autoconsciência) quando o conhecimento objetivo sejam condições da consciência dos nossos estados internos, não implica nenhuma conclusão acerca da hierarquia epistêmica que situa, um em relação ao outro, esses dois princípio condicionantes. Nesse sentido, refutar o primado da consciência dos estados internos em relação ao conhecimento objetivo (projeto da Refutação) não é o mesmo que refutar o primado, sobre o mesmo conhecimento, de algum outro princípio que essa consciência supõe e que, com efeito, a condiciona. Em suma, aceito o argumento da Refutação, ainda é possível que o elemento subjacente à consciência do fluxo perceptivo interno se apresente em última instância como a autoconsciência de um sujeito numericamente idêntico, e que esta preceda do ponto de vista epistêmicometodológico ou mesmo constitua ontologicamente (na condição de ratio essendi) o domínio do conhecimento objetivo ${ }^{27}$. Trata-se, portanto, aqui, de

24 São eles: ALMEIDA, G. "Consciência de si e conhecimento objetivo na Dedução Transcendental da Crítica da Razão Pura”. In : Analytica. v.1, n¹, 1993, pp.187-219 e o supracitado ALMEIDA, 1998, pp.135-156.

25 ALMEIDA, 1998, p. 137 e 137n. Chamo a atenção para a análise que o comentador propõe para a ambivalência da expressão "an die Hand geben", empregada por Kant nessa passagem, bem como para a de outras seis passagens da edição A, em ALMEIDA, G. 1993, p. 192ss.

26 ALMEIDA, 1998, pp.137-8.

27 Com respeito ao ponto, a posição de Lachièze-Rey, da qual divergimos, é a de que o argumento da Dedução não confronta essa hipótese, o que cremos ser equivalente a afirmar que "Kant, apesar de certas aparências, reconhece em suma a autonomia e a independência do princípio cartesiano" (LACHIÈZE-REY, P. 1972, p.63). Para Guido Almeida, é apenas a versão A da Dedução que pode ser vista como "trazendo algum apoio para a interpretação ‘cartesianizante' da Dedução” (ALMEIDA, G. 1998, p.150). 
uma discussão que ultrapassa o confronto com idealista cético para contrapor o projeto refutativo kantiano com o interlocutor que temos chamado de idealista da autoconsciência.

É bem verdade que um dos passos da Refutação consiste na tese de que o interior do domínio representacional não seria capaz de fornecer o contraponto permanente indispensável para a possibilidade da consciência da sucessão das percepções. Essa restrição, de fato, desclassificaria a candidatura da autoconsciência (evidentemente representacional) ao posto ${ }^{28}$. Mas não menos os objetos espaciais, na medida em que entendidos como "meras representações" do sentido externo. Seja como for, o mencionado passo da Refutação precisa ser embasado por uma demonstração de que o mais forte candidato representacional a princípio e condição do conhecimento objetivo (qual seja, a unidade e identidade numérica do sujeito autoconsciente, que é uma condição da consciência do fluxo perceptivo) só é capaz de fornecer o buscado contraponto permanente na medida em que, inversamente, se encontra subordinado ao - ou pelo menos não seja anterior e epistemicamente independente do - domínio de uma exterioridade objetiva, esta sim o permanente último.

Novamente, é na Dedução Transcendental, e não na Refutação do Idealismo, que acreditamos encontrar um esboço de refutação desse interlocutor remanescente, idealista, mas absolutamente não-cético em matéria de conhecimento, que apenas sustenta o primado epistêmico da autoconsciência em relação ao conhecimento de objetos. Trata-se de discutir, primeiro, em que medida é a ele, e não ao interlocutor da Refutação, que cabe legitimamente o epíteto de "idealista cartesiano"; e em seguida, como a Dedução se comporta em relação à sua posição gnosiológica.

Quanto ao primeiro ponto, é surpreendente que tanto no quarto Paralogismo de 81, quanto na Refutação B, Kant faça explícita referência a Descartes como interlocutor do argumento que ali se desenvolve.

28 ponto é controverso também na leitura de Guyer. Após analisar o que identifica como os três os argumentos essenciais da primeira analogia da experiência para a conexão entre determinação temporal e permanência, o comentador permanece com a questão: "mesmo que se admita que a determinação temporal exige algo que permaneça, não é óbvio por que esse algo não pode ser um Eu permanente", e que devam ser "objetos que são externos ao Eu, seja apenas como fenomenologicamente espaciais, seja 'no sentido transcendental', isto é, numericamente distintos do Eu e, em sua existência, independentes das nossas representações" (GUYER, 1987, p.283). 
Registre-se, em primeiro lugar, que o adversário da Refutação é alguém que advoga o privilégio da "experiência interna" relativamente à externa. Mas a proposição cartesiana Eu penso, eu existo, derivada exclusivamente do exercício do ato de pensar e imediatamente acessível (ao contrário do conhecimento de "realidades externas"), é no mínimo problematicamente traduzida pelo conceito kantiano de "experiência interna". Em Descartes encontramos antes o primado epistêmico de um conhecimento de si que prescinde de sensibilidade, o que para Kant, além de não se chamar "experiência”, é epistemicamente inaceitável.

Em segundo lugar, a Refutação é explicitamente caracterizada como um argumento contra o idealista empírico, portanto, contra o cético em matéria de conhecimento. Isso parece implicar que o Descartes de Kant é alguém que, após haver constatado a impossibilidade de um acesso perceptivo imediato a objetos externos, teria abandonado o projeto de chegar a eles pelo duvidoso caminho da inferência causal, e teria sucumbido à tese do confinamento do sujeito ao mundo interno das representações, que seria o mundo das percepções dos seus estados indiscriminadamente subjetivos. Ademais, visto que ele não afirmaria a impossibilidade, mas apenas duvidaria da possibilidade de um conhecimento de objetos externos, mereceria o honroso título de "idealista cético", "benfeitor da razão humana" (A377), que, ao contrário do idealista chamado dogmático, estimularia a razão crítica ao exercício das reflexões na direção da inversão copernicana no domínio da filosofia.

Mas como bem se sabe, após haver duvidado sistematicamente da existência do mundo exterior até determinado momento da construção do sistema das Meditações, Descartes não somente pretende fornecer uma prova da existência e da cognoscibilidade do mundo exterior (em sentido absoluto, não-interiorizado), como também emprega, com esse fim, uma teoria da causalidade, o que é para Kant explicitamente inaceitável e incompatível com o perfil do interlocutor cético da Refutação. Ao lado da doutrina segundo a qual o conteúdo das ideias são realidades objetivas, Descartes busca provar existência e cognoscibilidade do "fora de nós" aplicando a noção de causalidade, se não indiscriminadamente ao domínio das ideias (às chamadas ideias sensíveis), pelo menos a uma ideia, a saber, a do infinito. Assim, podemos afirmar que o idealista problemático, empírico, cético, não-dogmático e não-irracional que Kant procura e quer ver em Descartes na Refutação é o Descartes que, partindo da dúvida e passando pela inferência "eu penso", pára na conclusão "eu existo". Portanto, não é Descartes.

Balanço feito, tudo indica que a posição final da gnosiologia cartesiana está muito mais próxima do que nomeamos aqui idealismo da autoconsciência, que 
funciona na Lógica Transcendental como um dos adversários da Dedução ${ }^{29}$, e não da Refutação - a qual se volta contra o idealismo cético. Em primeiro lugar, porque se pudéssemos traduzir o Eu penso, eu sou cartesiano pela noção kantiana de "experiência interna", deveríamos dizer que são ao mesmo tempo cartesianas e não-céticas as teses de que "a única experiência imediata é a experiência interna", e que "a partir dela inferimos [a existência das] coisas externas". Em segundo, porque, a rigor, não podemos traduzir o Eu penso, eu sou cartesiano pela kantiana "experiência interna". A versão cartesiana desta expressão, indicada na proposição Eu penso, deve, ao contrário da kantiana, designar um ato exclusivo do pensamento, o qual é para Kant sempre précognitivo, não-experiencial e, a rigor, apenas aperceptivo. E queremos crer que é a Dedução que se acha comprometida com a tese de que a "experiência externa a rigor é imediata" e "somente por seu intermédio é possível..." o $E u$ penso como expressão da unidade transcendental da apercepção. Chegamos com isso à segunda pergunta acima formulada: como a Dedução se comporta em relação ao idealismo cartesiano da autoconsciência?

Já no §16, Kant manifesta alguma preocupação com ele imediatamente após inferir a unidade originária da apercepção a partir do conceito de um múltiplo de representações consideradas como minhas. Sobre "essa identidade completa da apercepção de um múltiplo dado na intuição", afirma que ela "contém (enthält) uma síntese de representações, e só é possível pela (ist nur durch...möglich) consciência dessa síntese" (B133).

De um lado, o vocabulário da continência não desautoriza a tese da independência e do primado da apercepção relativamente ao múltiplo de representações dadas. Com efeito, é razoável aceitar que o que contém subsista anterior ao e independentemente do seu conteúdo, a ponto de poder ser mais imediatamente cognoscível do que ele e "aplicável" a ele. Esse modo de caracterizar a relação entre a unidade da apercepção e as representações dadas soa cúmplice de leituras cartesianizantes do kantismo, que concebem a consciência de si como anterior e principial relativamente às representações sintetizadas, aplicando-se tardiamente a elas de modo a conferir objetividade à síntese contingente e pré-aperceptiva em que originalmente se organizariam ${ }^{30}$.

29 E aqui colidimos com a leitura de Lachièze-Rey. Cf. nota 27.

30 Para Guido Almeida, a versão A pode ser vista como "trazendo algum apoio para a interpretação 'cartesianizante' da Dedução" na medida em que "os conceitos pelos quais se pensa a unidade da síntese são apresentados como o fruto da relação da apercepção com a síntese da imaginação. (...) Sendo a síntese em si mesma 'sensível', ela é incapaz de assegurar por si a unidade das intuições segundo conceitos de objetos. Para isso, é preciso que ela seja 'intelectualizada', o que acontece justamente quando a apercepção 'se acrescenta' à imaginação e é a esse 'acréscimo' da apercepção ao múltiplo sintetizado pela imaginação que devemos o surgimento dos conceitos de objetos” (ALMEIDA, 1993, 
O complemento da passagem, cuja conjunção, queremos crer, deve ser interpretada como explicativa, parece, no entanto, bloquear essa leitura. Ao mesmo tempo em que revela o princípio de unificação de um múltiplo dado, a apercepção é tornada primeiramente possível pelas representações cujo caráter de um múltiplo ou série ela revela ${ }^{31}$. Nesse sentido, enquanto consciência de um Eu subjacente espontâneo que, em princípio, nada é senão o caráter de série da série das representações enquanto minhas, a apercepção não subsiste independentemente dos elementos da série representativa, não confere gênese aos objetos ordenados, nem consiste num conhecimento anterior ao conhecimento dos elementos da série representativa. Em suma, Kant aqui parece não pretender atribuir à autoconsciência nem um primado ontológico, nem um primado epistêmico em relação à consciência dos objetos representados.

Sabe-se que na chamada primeira parte da Dedução, os objetos representacionais relativamente aos quais Kant pretende demonstrar a validade objetiva da apercepção transcendental são "intuições em geral". Mas a tarefa da segunda parte, associada à da Refutação, é concluir aquela demonstração apresentando a relação da apercepção especificamente com os dados de nossa intuição sensível espaço-temporal, vale dizer, com os objetos do nosso conhecimento. Se isso se faz, pode-se dizer que a autoconsciência tampouco possui algum primado (ontológico / epistêmico) em relação ao domínio dos objetos do conhecimento. Ao contrário, é somente na medida em que me torno explicitamente consciente de representações enquanto minhas, e não primeiramente de mim mesmo, que posso me tornar consciente de mim mesmo como princípio subjacente da unidade delas.

\section{Sobre a possibilidade do idealismo irrefutado}

Encontra-se na Dedução um emprego terminológico que identifica a prova anti-idealista do primado do "domínio da objetividade" em relação à autoconsciência com uma prova do caráter "originário" da chamada unidade objetiva da apercepção. Esse emprego é acompanhado de importantes

p.211). E noutra parte: "A consciência de si aparece aqui, pois, pode-se dizer, como uma ratio essendi do pensamento de objetos e, por conseguinte, como uma fonte das categorias ou o princípio que permite explicar sua gênese" (op.cit. p.190).

31 Paton chama a atenção para essa relação de mão-dupla nos seguintes termos: "Até agora vimos que se representações devem ser representações de um objeto, elas devem ser unificadas num ato de pensamento potencialmente autoconsciente; em outros termos, elas devem estar relacionadas à unidade da apercepção. Devemos agora considerar isso pelo outro lado: a unidade da apercepção é ela mesma impossível separada da síntese do múltiplo dado, bem como da consciência dessa síntese. Como sempre em Kant, a unidade da apercepção e a unidade do múltiplo condicionam-se reciprocamente, se é que elas não devem ser consideradas como idênticas" (PATON, 1965, p.512). 
decisões conceituais. Sabe-se que a palavra Apperzeption, tradução da latina conscientia, originalmente não tem conotação reflexiva ${ }^{32}$. Apperzeption como autoconsciência - consciência de si de um sujeito como sujeito uno e idêntico da pluralidade das suas representações - é um uso tardio. Sabese também que Kant se serve dos termos nos dois sentidos: consciência de si e consciência de objetos, de modo que a unidade objetiva da apercepção pode ser ou bem a consciência da unidade de um $\mathrm{Eu}$, ou bem unidade da consciência de estados de coisas objetivos como resultado do recolhimento das intuições a conceitos de objetos em juízos ${ }^{33}$. Tudo indica que é o segundo sentido que Kant confere à expressão quando se trata de refutar o suposto primado epistêmico cartesiano (idealista problemático) da autoconsciência subjetiva. A tese de que o mundo externo é mais imediatamente cognoscível seria assim expressa por Kant como a tese do primado da unidade objetiva da Apperzeption como consciência de objetos. O elemento originário suposto em toda consciência que o sujeito tem de si mesmo (seja na consciência empírica dos estados internos, seja na consciência de si como sujeito lógico do ato de pensar) é uma consciência de estados objetivos. Em suma, a consciência do Eu só é possível sob o pressuposto de que é possível a consciência do não-Eu.

O que se pergunta, por fim, é se com essa demonstração Kant consegue se ver livre de todo idealismo indesejável e estabelecer o idealismo transcendental como, segundo a letra do Prefácio, o caminho seguro de uma metafísica purificada pela Crítica. Alguma ameaça idealista ainda permanece quando o refutador do idealismo julga ter encontrado o elemento originário e o princípio último de sua concepção do conhecimento na noção de apercepção objetiva, consciência de objetos? Ainda que não se interprete esse dado originário que parece ser a unidade objetiva da apercepção como consciência de si, ela permanece uma forma de consciência, a saber, da unidade das representações enquanto representações de um objeto. Isso pode manter aberta a possibilidade de que o domínio da objetividade seja epistemicamente anterior à autoconsciência somente na medida em que resulta da atividade constituinte de uma consciência que se atualiza nas formas lógicas do julgar. E talvez deva ser preciso evitar que a Dedução apareça, ao fim e ao cabo, como a prova de um primado, se não epistêmico-metodológico, ao menos transcendental, do Eu puro como consciência transcendental em relação ao domínio da objetividade. 
Enfim, pertence à letra e ao espírito do kantismo uma refutação do que pode vir a ser esse idealismo remanescente em sua versão mais radical? Uma refutação que se apresente como a prova não só de que a consciência da unidade e identidade de um Eu puro depende do conhecimento objetivo, mas também de que a unidade e identidade da consciência objetiva se constitui a partir de (e em cooperação com) uma "objetividade" ante-representacional e, a rigor, pré-consciente... Talvez seja isso, afinal, assimilar, sem realismo simplista, a ideia de que algo só pode merecer o título de Gegenstand se lhe pertence uma incontornável alteridade em relação ao Eu, ou por outras, se estiver absolutamente lá: "fora de nós".

\section{Referências bibliográficas}

ALLISON, H. - Kant's Theory of Taste. Cambridge: Cambridge University Press 2001 ALLISON, H. - Kant's Transcendental Idealism: an interpretation and defense. (revised \& enlarged edition) New Haven and London: Yale University Press 2004 ALLISON, H. - Kant's Transcendental Idealism: an interpretation and defense. New Haven and London: Yale University Press 1983.

ALMEIDA, G. - "Consciência de si e conhecimento objetivo na Dedução Transcendental da Crítica da Razão Pura". In : Analytica. v.1, nº 1, 1993

ALMEIDA, G. - "Dedução Transcendental: o cartesianismo posto em questão". In: Analytica. v. $3, \mathrm{n}^{\circ} 1,1998$

AMERIKS, K. - “Kant's Transcendental Deduction as a Regressive Argument”. KantStudien 69, 1978

McCANN, E. - "Skepticism and Kant's B Deduction”. In: History of Philosophy Quarterly 2 (January 1985)

GUYER, P. - Kant and the Claims of Knowledge. Cambridge: Cambridge University Press 1987

KANT, I. - Kritik der Reinen Venunft. Hamburg: Felix Meiner 1990

KANT, I. - Werke in zehn Bänden. Hrsg. Wilhelm Weischedel. Darmstadt: Wissenschaftliche Buchgesellschaft, 1983

LACHIÈZE-REY, P. - L'idéalisme kantien. Paris: J. Vrin 1972

LONGUENESSE, B. - "An Interview with Béatrice Longuenesse”. In: The Dualist: Stanford's Undergraduate Journal of Phylosophy, Vol. XII, № 1, Autumn 2005, 67-81 LONGUENESSE, B. - "Kant's 'I think' versus Descartes' 'I am a thing that thinks' ". In: Kant and the Early Moderns. Ed. Longuenesse, B. \& Garber, D. Princeton: Princeton University Press 2008

LONGUENESSE, B. - Kant and the Capacity to Judge. Princeton and Oxford: Princeton University Press 1998

PATON, H. J. - Kant's Metaphysic of Experience. New York: George Allen \& Unwin LTD, The Humanities Press $1965,4^{\text {th }}$ impression

PRAUSS, G. - Erscheinung bei Kant. Berlin: de Gruyter 1971 